\title{
ESTABELECIMENTO E MULTIPLICAÇÃO IN VITRO DE PORTA-ENXERTOS DE Prunus ${ }^{1}$
}

\author{
APARECIDO LIMA DA SILVA², MARCELO ROGALSKI ${ }^{3}$, LIZIANE KADINE ANTUNES DE MORAES ${ }^{4}$, CLAUDIA \\ FESLIBINO $^{5}$, LEANDRO CRESTANI ${ }^{6}$, MIGUEL PEDRO GUERRA $^{7}$
}

\begin{abstract}
RESUMO - A qualidade genética e sanitária das mudas é de fundamental importância para o sucesso da fruticultura moderna. Para o pessegueiro, a micropropagação vem permitindo a produção clonal massal de plantas, com matrizes e mudas de qualidade genética-sanitária comprovada. O presente trabalho objetivou avaliar a taxa de sobrevivência de explantes no estabelecimento in vitro, bem como avaliar o potencial de multiplicação in vitro de porta-enxertos de Prunus. Explantes constituídos por ápices caulinares e gemas laterais dos porta-enxertos Capdeboscq e GF677 e da seleção VP411 foram estabelecidos e multiplicados in vitro em meio de cultura de Lepoivre suplementado com BAP $\left(0,5 \mathrm{mg} . \mathrm{L}^{-1}\right)$. A taxa média de sobrevivência para os porta-enxertos foi 62,9\% para ápices caulinares e 58,8\% para gemas laterais. Ápices caulinares e gemas laterais apresentaram 14,8\% e 29,8\% de contaminação, respectivamente. O genótipo afetou significativamente as taxas de multiplicação in vitro. Quanto ao número de brotos por explantes, o porta-enxerto Capdeboscq e a seleção VP411 foram superiores ao porta-enxerto GF677, resultando em 14,7; 16,0 e 10,5 brotos, respectivamente. Para a altura média dos brotos, os porta-enxertos Capdeboscq e GF677 foram superiores à seleção VP411 com 9,3; 8,9 e 7,8 mm, respectivamente. O portaenxerto Capdeboscq foi superior ao porta-enxerto GF677 e à seleção VP411 na variável número de brotos >20 mm com 2,0; 1,3 e 1,0 brotos, respectivamente.
\end{abstract}

Termos para indexação: Pessegueiro, porta-enxertos, BAP, micropropagação, mudas.

\section{IN VITRO ESTABLISHMENT AND MULTIPLICATION OF PRUNUS ROOTSTOCKS}

\begin{abstract}
The success of the modern fruit production depend on the genetic and sanitary quality of plants. For the peach tree culture, micropropagation techniques allow a mass clonal production with high genetic quality plants. The present study aimed to evaluate the explant survival rate during in vitro establishment period, as well as to evaluate the in vitro multiplication potential of Prunus rootstocks. Apexes and lateral buds of the rootstocks Capdeboscq and GF677 and of the selection VP411 were introduced in vitro in the Lepoivre's medium supplemented with BAP $\left(0.5 \mathrm{mg} . \mathrm{L}^{-1}\right)$. The mean values of explant survival for the rootstocks were $62.9 \%$ and $58.8 \%$, for apexes and lateral buds, respectively. Cultures of apexes and lateral buds showed $14.8 \%$ and $29.8 \%$ of contamination, respectively. The genotype significantly affected the in vitro multiplication rates. The rootstocks Capdeboscq and GF677, and the selection VP411 showed multiplication rates of 14.7, 10.5 and 16.0 shoots/explant, respectively. As mean values for shoot height of the rootstocks Capdeboscq and GF677 and of the selection VP411, it was observed 9.3, 8.9 and 7.8 mm, respectively. The rootstock Capdeboscq showed superior values as regarded to the number of shoots $>20 \mathrm{~mm}$ as compared to rootstock GF677 and selection VP411 with values of 2.0, 1.3 and 1.0 of shoots, respectively.
\end{abstract}

Index terms: Peach tree, rootstock, BAP, micropropagation, plant stock.

\section{INTRODUÇÃO}

No Brasil e principalmente nas regiões Sul e Sudeste, a cultura do pessegueiro apresenta uma grande importância socioeconômica, ocupando uma área superior a 20 mil hectares, com uma produção estimada em 150 mil toneladas (Sachs \& Campos, 1998). Os Estados do Rio Grande do Sul e Santa Catarina destacam-se como os maiores produtores do País com áreas de 11,9 e 4,5 mil hectares, respectivamente (Epagri, 2001).

Na cultura do pessegueiro, um sistema moderno e tecnificado é determinante para a qualidade dos frutos e para a obtenção de uma alta produtividade dos pomares. Neste contexto, a muda é um insumo básico de fundamental importância para o sucesso na atividade (Fachinello, 2000).

Contudo, o sistema de produção de mudas de pessegueiro no Sul do Brasil ainda repousa sobre o emprego de porta-enxertos obtidos de sementes da indústria de conserva, aspecto este que permite a ocorrência de misturas varietais e conseqüente desuniformidade de plantas, a morte precoce de plantas e a falta de uniformidade genética (Fachinello, 2000).

Na propagação vegetativa, via estaquia, a principal limitação é a baixa capacidade de enraizamento para a maioria das cultivares de pessegueiro, aliada ao forte efeito do genótipo, com resultados variáveis de acordo com as cultivares utilizadas (Fachinello et al., 1995; Rufato \& Kersten, 2000).
A tecnologia de cultura in vitro tem permitido propagar espécies de difícil multiplicação, com obtenção de material de alta qualidade genética através da captura e fixação de ganhos genéticos a partir de genótipos superiores. Para o gênero Prunus, o sucesso no estabelecimento e na multiplicação in vitro foi descrito pôr vários autores (Hammerschlag, 1982; Pérez -Tornero \& Burgos, 2000).

No Brasil, os trabalhos de micropropagação do gênero Prunus, especialmente para o pessegueiro, são relativamente escassos. Recentemente, Rodrigues et al. (1999) e Silveira et al. (2001) demonstraram as dificuldades em estabelecer e multiplicar in vitro porta-enxertos de Prunus.

No presente trabalho, foram estudados os fatores associados ao estabelecimento e multiplicação in vitro dos porta-enxertos Capdeboscq e GF677 e da seleção VP411, visando à propagação clonal.

\section{MATERIALEMÉTODOS}

\section{Material vegetal}

Os porta-enxertos selecionados foram: a) Capdeboscq - Prunus persica (L.) Batsch é a cultivar mais utilizada no Sul do Brasil para a produção de mudas de pessegueiro e ameixeira; cultivar de ciclo tardio apresenta uma boa germinação das sementes; b) GF677 - Prunus amygdalus x Prunus persica possui como característica a robustez decorrente do vigor híbrido, bem como boa compatibilidade com ambas as

\footnotetext{
${ }^{1}$ (Trabalho 158/2002). Recebido: 26/09/2002. Aceito para publicação: 18/07/2003.

${ }^{2}$ Prof. Adjunto da Universidade Federal de Santa Catarina, Departamento de Fitotecnia, C.P. 476, 88040-900, Florianópolis-SC, (48) 331-5330, alsilva@ cca.ufsc.br.

${ }^{3}$ Biólogo, Mestre, Universidade Federal de Santa Catarina, Departamento de Fitotecnia, C.P. 476, 88040-900, Florianópolis-SC, (48) 331-5330.

${ }^{4}$ Acadêmica em Agronomia da Universidade Federal de Santa Catarina, C.P. 476, 88040-900, Florianópolis-SC, (48) 331-5330, bolsista RHAE/CNPq.

${ }^{5}$ Acadêmica em Biologia da Universidade do Oeste de Santa Catarina, C.P. 187, 89560-000, Videira-SC, (49) 551-1422, bolsista RHAE/CNPq.

${ }^{6}$ Eng $^{\circ}$. Agr ${ }^{\circ}$. Empresa Vitroplanta - Biotecnologia Ltda, C.P. 150, 89560-000, Videira-SC, (49) 566-2690, bolsista RHAE/CNPq.

${ }^{7}$ Professor Titular da Universidade Federal de Santa Catarina, Departamento de Fitotecnia, C.P. 476, 88040-900, Florianópolis-SC, (48) 331-5330.
} 
espécies e tem demonstrado ótimo potencial para a propagação comercial através da micropropagação; c) VP411 - é uma seleção de Capdeboscq, obtida pela Vitroplanta - Biotecnologia Vegetal Ltda (Videira/SC), e encontra-se em testes como porta-enxerto para a redução do porte e melhor qualidade dos frutos em ameixeira.

As plantas-matrizes destes porta-enxertos foram mantidas em casa de vegetação do Departamento de Fitotecnia/CCA/UFSC e na Vitroplanta em Videira (SC).

\section{Estabelecimento in vitro}

Os experimentos de cultura in vitro foram conduzidos no Laboratório de Morfogênese e Bioquímica Vegetal do Departamento de Fitotecnia/CCA/UFSC. Das plantas-matrizes foram coletados brotos com crescimento ativo, que foram seccionados em segmentos de três a quatro gemas e posteriormente submetidos ao seguinte processo de desinfestação: lavagem em água e detergente (10 gotas. L $^{-1}$ de Tween 20$)$ e, posteriormente, sob agitação por 1 minuto em etanol 70\%, 15 minutos em hipoclorito de sódio $(1,25 \%)$ e, finalmente, em câmara de fluxo laminar, os explantes foram submetidos a três lavagens com água destilada autoclavada.

Os ápices caulinares e gemas laterais foram inoculados em tubos de ensaio $(25 \mathrm{x} 150 \mathrm{~mm})$ contendo $10 \mathrm{~mL}$ de meio de cultura composto de sais e vitaminas de Lepoivre (Quoirin et al., 1977), suplementado com sacarose (20g. $\left.\mathrm{L}^{-1}\right)$, ágar $\left(7 \mathrm{~g} . \mathrm{L}^{-1}\right)$ e 6-benzilaminopurina (BAP) $\left(0,5 \mathrm{mg} . \mathrm{L}^{-1}\right)$

Após 30 dias, ápices caulinares e gemas laterais foram avaliados quanto ao índice de sobrevivência e contaminação.

\section{Multiplicação in vitro}

O material vegetal foi multiplicado, com subculturas a cada 21 dias, através de segmentos nodais com 1-2cm, desprovidos dos ápices caulinares, no mesmo meio de cultura citado anteriormente na fase de estabelecimento.

$\mathrm{Na}$ terceira subcultura in vitro, após 28 dias de cultivo, os dados referentes à multiplicação in vitro dos porta-enxertos Capdeboscq e GF677, e da seleção VP411 foram avaliados quanto ao número de brotos por explante, altura média das brotações $(\mathrm{mm})$ e número de brotos $>20 \mathrm{~mm}$ por explante.

\section{Condições de cultura in vitro}

Para as diferentes fases, o $\mathrm{pH}$ do meio de cultura foi ajustado para 5,2-5,3 e todos os componentes do meio foram adicionados antes da autoclavagem a $121^{\circ} \mathrm{C}$, durante 15 minutos. O material vegetal foi mantido em câmara de crescimento com temperatura de $25 \pm 2^{\circ} \mathrm{C}$, fotoperíodo de 16 horas e intensidade luminosa de $40-45 \mu \mathrm{mol} . \mathrm{m}^{-2} . \mathrm{s}^{-1}$, fornecidas pôr lâmpadas fluorescentes brancas frias.

\section{Análises estatísticas}

$\mathrm{Na}$ fase de estabelecimento in vitro, os dados foram avaliados quanto às porcentagens de sobrevivência e contaminação. Para a fase de multiplicação in vitro, utilizou-se o delineamento experimental inteiramente ao acaso, com cinco explantes por repetição e cinco repetições por tratamento. Os dados de número de brotos por explante, altura média das brotações $(\mathrm{mm})$ e número de brotos $>20 \mathrm{~mm}$ por explante foram submetidos à Análise de Variância (ANOVA) e ao teste de separação de médias SNK (5\%), de acordo com Sokal e Rohlf (1995).

\section{RESULTADOSE DISCUSSÃO}

\section{Estabelecimento in vitro}

Os valores observados para os diferentes explantes no estabelecimento in vitro dos três porta-enxertos estão apresentados na Tabela 1. As percentagens médias de sobrevivência de ápices caulinares e gemas laterais foram, respectivamente, de $62,9 \%$ e 58,8\%. Estes resultados podem ser considerados eficazes para introdução in vitro de porta-enxertos de Prunus e estão entre os limites de sobrevivência (27\% a 93\%) obtidos por Hammerschlag (1982), no estabelecimento in vitro de 11 cultivares de pessegueiro.

Os explantes de ápices caulinares e gemas laterais apresentaram taxas de $14,8 \%$ e $29,8 \%$ de contaminação, respectivamente (Tabela 1). Verifica-se que estes índices foram inferiores a outros estudos já realizados. Rodrigues et al. (1999) obtiveram taxas de 50\% a 95,8\% de contaminação no estabelecimento in vitro de seis porta-enxertos de Prunus. Estes autores constataram maior contaminação de gemas laterais e um efeito significativo do genótipo na fase de estabelecimento in vitro. Hammerschlag (1982) observou maior ocorrência de contaminação (70\%) em gemas dormentes, enquanto, para brotos com crescimento ativo, a taxa de contaminação foi de $27 \%$, no estabelecimento in vitro de pessegueiro.

Pode-se destacar que a metodologia usada neste trabalho para introdução e estabelecimento in vitro com explantes originários de plantas-matrizes mantidas em casa de vegetação, com controle sanitário e nutricional, permitiu bons resultados no estabelecimento in vitro para o material estudado, apresentando baixos índices de contaminação por agentes patogênicos (Figuras 1a e b).
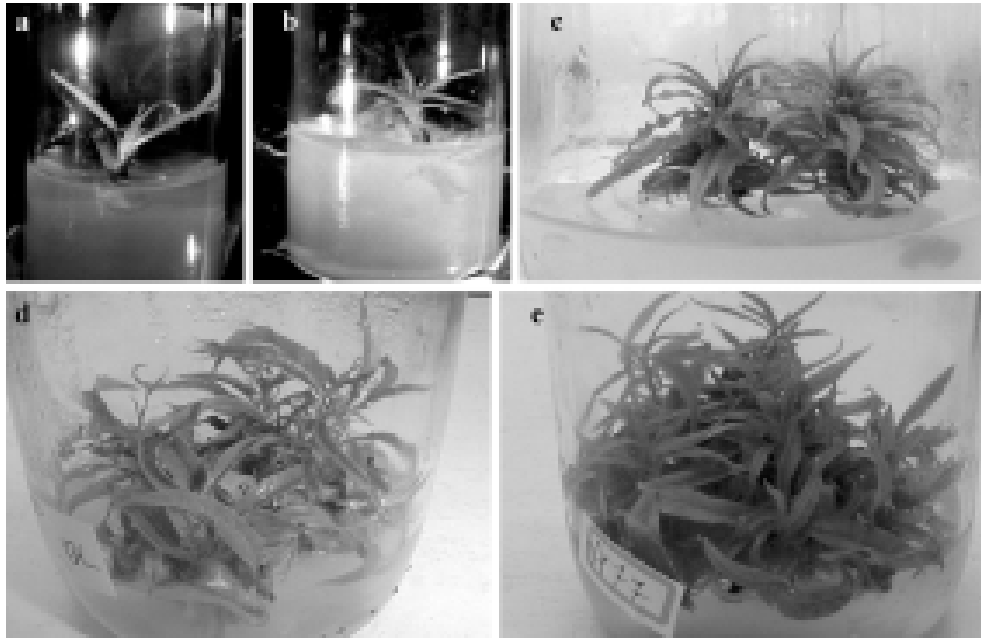

FIGURA 1 - Aspectos morfogenéticos no estabelecimento e multiplicação in vitro de porta-enxertos de Prunus. a) gema lateral. b) ápice caulinar. c) primeira subcultura. d) segunda subcultura. e) explante em multiplicação. UFSC, Florianópolis-SC, 2002.

\section{Multiplicação in vitro}

Já no primeiro subcultivo, observou-se que as culturas apresentaram alto potencial de multiplicação in vitro (Figura 1). O genótipo apresentou efeito altamente significativo em relação ao número de brotos, altura média dos brotos e ao número de brotos $>20 \mathrm{~mm}$ por explante. Os porta-enxertos Capdeboscq e GF677 e a seleção VP411 pro-

TABELA 1 - Porcentagens de sobrevivência e contaminação observadas no estabelecimento in vitro dos porta-enxertos Capdeboscq e GF677, e da seleção VP411. UFSC, Florianópolis-SC, 2002.

\begin{tabular}{ccccccc}
\hline & Total & Total & \multicolumn{2}{c}{ Sobrevivência (\%) } & \multicolumn{2}{c}{ Contaminação (\%) } \\
Porta-enxertos & Ápices caulinares & Gemas laterais & Ápices caulinares & Gemas laterais & Ápices caulinares & Gemas laterais \\
\hline Capdeboscq & 9 & 30 & 55,5 & 63,3 & 11,1 & 6,6 \\
GF677 & 5 & 17 & 100,0 & 58,8 & 0,0 & 41,2 \\
VP411 & 3 & 24 & 33,3 & 54,2 & $\mathbf{5 8 , 8}$ & $\mathbf{1 4 , 8}$ \\
\hline Total & $\mathbf{1 7}$ & $\mathbf{7 1}$ & $\mathbf{6 2 , 9}$ & &
\end{tabular}


duziram valores médios de 14,7; 10,5 e 16,0 brotos por explantes, respectivamente. O porta-enxerto Capdeboscq e a seleção VP411 não apresentaram diferenças significativas entre si para este parâmetro, mas foram significativamente superiores ao porta-enxerto GF677 (Figura 2). Estes resultados foram superiores aos obtidos por Parfitt e Almehdi (1986), que avaliaram a multiplicação in vitro de 56 cultivares e observaram uma variação de 1,3 a 9,9 brotos por explante, com a utilização do meio de

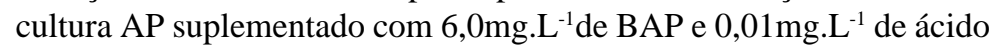
indolbutírico.

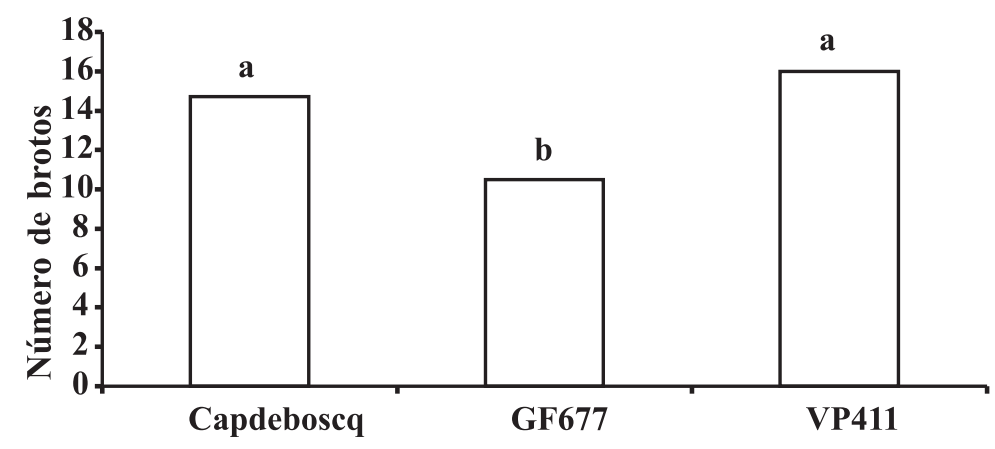

FIGURA 2 - Número de brotos por explante para os porta-enxertos Capdeboscq e GF677, e a seleção VP411, após 28 dias de cultura em meio de cultura de Lepoivre suplementado com BAP (0,5mg.L-1). UFSC, Florianópolis-SC, 2002.

No presente trabalho, a utilização do meio de cultura de Lepoivre mostrou-se adequada para a multiplicação dos genótipos estudados. Sabe-se que a constituição basal do meio de cultura, o tipo e a concentração dos reguladores de crescimento são fatores determinantes para a obtenção de altas taxas de multiplicação in vitro, em diferentes genótipos do gênero Prunus (Arena \& Caso, 1992; Pérez-Tornero \& Burgos, 2000; Pérez-Tornero et al., 2000).

Para a altura média dos brotos, os porta-enxertos Capdeboscq e GF677, com altura de 9,3 e 8,9 mm, respectivamente, apresentaram maior crescimento, diferindo significativamente da seleção VP411 com altura de 7,8mm (Figura 3). A altura média dos brotos é uma variável determinada principalmente pela concentração e tipo do regulador de crescimento (Harada \& Murai, 1996; Leontiev-Orlov et al., 2000), meios de cultura (Arena \& Caso, 1992; Pérez-Tornero \& Burgos, 2000; PérezTornero et al., 2000) e genótipo (Arena \& Caso, 1992; Pérez-Tornero \& Burgos, 2000).

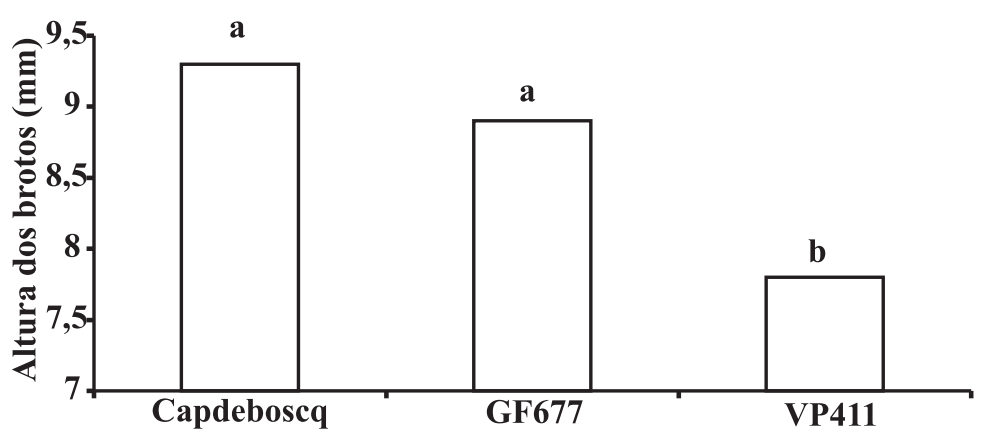

FIGURA 3 - Altura média dos brotos (mm), para os porta-enxertos Capdeboscq e GF677, e a seleção VP411, após 28 dias de cultura em meio de cultura de Lepoivre suplementado com BAP (0,5mg.L $\left.\mathrm{L}^{-1}\right)$. UFSC, Florianópolis-SC, 2002.

Em relação ao número de brotos maiores que $20 \mathrm{~mm}$ por explante, o porta-enxerto Capdeboscq resultou em 2,0 brotos, sendo significativamente superior ao porta-enxerto GF677 e à seleção VP411 com 1,3 e 1,0 brotos, respectivamente (Figura 4). Esta variável é de grande importância para a próxima fase da micropropagação, o enraizamento in vitro. Para Harada \& Murai (1996) e Leontiev-Orlov et al. (2000), a obtenção de brotos aptos para o enraizamento, maiores que $20 \mathrm{~mm}$, tem sido difícil para algumas espécies do gênero Prunus. Entretanto, com resultados similares ao observado neste trabalho, Arena \& Caso (1992) e PérezTornero et al. (2000) conseguiram obter com sucesso brotos com comprimentos adequados para o enraizamento in vitro de Prunus.

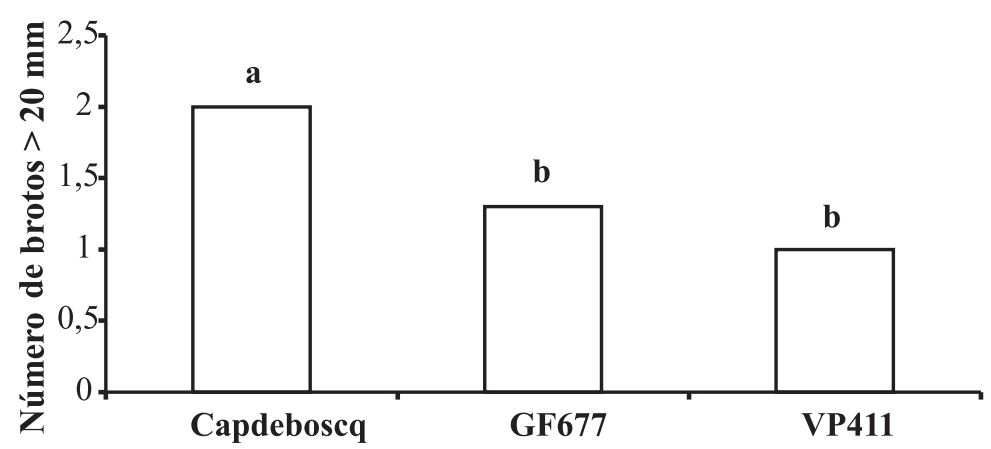

FIGURA 4 - Número de brotos > $20 \mathrm{~mm}$ para os porta-enxertos Capdeboscq e GF677, e a seleção VP411, após 28 dias em meio de cultura de Lepoivre suplementado com BAP $\left(0,5 \mathrm{mg} \cdot \mathrm{L}^{-1}\right)$. UFSC, Florianópolis-SC, 2002.

Os resultados obtidos no presente trabalho também confirmaram uma resposta dependente do genótipo de porta-enxertos de pessegueiro, com respeito ao meio de cultura, como demonstraram Parfitt \& Almehdi (1986), Arena \& Caso (1992) e Pérez-Tornero \& Burgos (2000) para diversas prunáceas. Isto poderia ser atribuído à necessidade de diferentes níveis de reguladores de crescimento suplementados ao meio de cultura, bem como a possíveis interações entre os reguladores de crescimento e os sais presentes no meio de cultura (Pérez-Tornero \& Burgos, 2000, Pérez-Tornero et al., 2000). Observa-se que algumas cultivares podem apresentar biossíntese diferencial de hormônios endógenos e/ou eficiência diferencial na absorção e metabolização dos compostos presentes no meio de cultura (Parfitt \& Almehdi, 1986). Associado a estes aspectos, os resultados obtidos no presente trabalho mostraram que os porta-enxertos Capdeboscq e GF677 e a seleção VP411 podem ser eficientemente estabelecidos, multiplicados e mantidos in vitro no meio de cultura Lepoivre.

\section{CONCLUSÕES}

Os resultados obtidos no presente trabalho permitem concluir que o estabelecimento e a multiplicação in vitro dos genótipos selecionados de Prunus pode ser eficientemente realizado a partir de ápices caulinares e gemas laterais inoculados em meio de cultura de Lepoivre, suplementado com BAP $\left(0,5 \mathrm{mg} \cdot \mathrm{L}^{-1}\right)$. A taxa de multiplicação in vitro foi de 14,$7 ; 10,5$ e 16,0 brotos/explante para os porta-enxertos Capdeboscq e GF677, e a seleção VP411, respectivamente. O porta-enxerto Capdeboscq foi superior para altura média das brotações e número de brotos $>20 \mathrm{~mm}$ por explante Estes valores são considerados satisfatórios para o estabelecimento de um protocolo de micropropagação dos genótipos mencionados.

\section{REFERÊNCIASBIBLIOGRÁFICAS}

ARENA, M.E.; CASO, O.H.Factores que afectan la multiplicación in vitro de los brotes de portainjertos de Prunus, ФYTON, Buenos Aires, v.53, p.29-38, 1992.

EMPRESA DEPESQUISA AGROPECUÁRIAEEXTENSÃORURALDE SANTA CATARINA S.A. Epagri. Frutas de clima temperado: situação da safra 1999-2000, Previsão da sagra 2000/2001. Videira: Epagri, 2001.21p.

FACHINELLO, J.C. Problemática das mudas de plantas frutíferas de caroço. In: SIMPÓSIO INTERNACIONAL DE FRUTAS DE CAROÇO: PÊSSEGOS, NECTARINAS E AMEIXAS, 1., 2000, Porto Alegre. Anais... p.25-40.

FACHINELLO, J.C.; HOFFMANN, A.; NACHTIGAL, J.C.; KERSTEN, E.; FORTES, G.R. de L. Propagação de plantas frutíferas de clima 
temperado. Pelotas-RS: Editora UFPel, 1995.178p.

HAMMERSCHLAG, F. Factors affecting establishment and growth of peach shoots in vitro, HortScience, Alexandria, v.17, n.1, p.85-86, 1982.

HARADA, H.; MURAI, Y. Micropropagation of Prunus mume. Plant Cell, Tissue and Organ Culture, Dordrecht, v.46, p.265-267, 1996.

LEONTIEV-ORLOV, O.; MOSSI, A. J.; CANSIAN, R.L.; ROGALSKI, M.; VENDRUSCOLO, T. Diferentes reguladores de crescimento na multiplicação in vitro de ameixeira (Prunus domestica L.) cultivar Kantimirovskaja, Revista Brasileira de Fruticultura, Jaboticabal, v. 22, n.2, p.268-271, 2000 .

PARFITT, D.E.; ALMEHDI, A.A. In vitro propagation of peach: II. A medium for in vitro multiplication of 56 peach cultivars, Fruit Varieties Journal, v.40, n.2, p.46-47, 1986.

PÉREZ-TORNERO, O.; BURGOS, L. Different media requirements for micropropagation of apricot cultivars, Plant Cell, Tissue and Organ Culture, Dordrecht, v.63, p.133-141, 2000.

PÉREZ-TORNERO, O.; LÓPEZ, J.M.; EGEA, J.; BURGOS, L. Effect of basal media and growth regulators on the in vitro propagation of apricot (Prunus armenica L.) cv. Canino, Journal of Horticultural Science \& Biotechnology, Ashford, v. 75, n.3, p.283-286, 2000.
QUOIRIN, M.; LEPOIVRE, P.; BOXUS, P. Un premier bilan de 10 années de recherches sur les cultures de méristèmes et la multiplication in vitro de fruitiers ligneux. Comptes Rendus des Recherches Agronomiques, Gembloux, p.93-117, 1977.

RODRIGUES, A.C.; FACHINELLO, J.C.; STRELOW, E.; FORTES, G.R. de L. Estabelecimento in vitro de porta-enxertos de Prunus sp., Revista Brasileira de Fruticultura, Cruz das Almas, v.21, n.2, p.229-231, 1999.

RUFATO, L.; KERSTEN, E. Enraizamento de estacas de pessegueiro (Prunus persica (L.) Batsch), cvs esmeralda e Br2, submetidas à estratificação e ao ácido indolbutírico, Revista Brasileira de Fruticultura, Jaboticabal, v.22, n.2, p.191-194, 2000.

SACHS, S.; CAMPOS, A.D. O Pessegueiro, In: MEDEIROS, C.A.B.; RASEIRA, M.C.B. A cultura do pessegueiro. Pelotas: EMBRAPACPACT, 1998.p.13-19.

SILVEIRA, C.A.P.; FACHINELLO, J.C.; FORTES, G.R. de L.; CITADIN, I.; RODRIGUES, A.C.; QUEZADA, A.C.; SILVA, J.B. da. Multiplicação in vitro de porta-enxertos do gênero Prunus sob diferentes concentrações de BAP em dois meios de cultura, Revista Brasileira de Fruticultura, Jaboticabal, v.23, n.3, p.488-492, 2001.

SOKAL, R.R.; ROHLF, F.J. Biometry. New York: W.H. Freeman and Company, 1995. 